\title{
Forebyggende behandling mot brennmanetskader - en randomisert studie
}

\author{
Engelsk oversettelse på www.tidsskriftet.no
}

\begin{abstract}
Sammendrag
Bakgrunn. Kontakt med brennmaneter kan gi irritasjon og utslett i huden. Vi $ø$ nsket å undersøke den forebyggende effekten av en brennmanetbeskyttende solkrem.
\end{abstract}

\begin{abstract}
Materiale og metode. Vi rekrutterte 38 personer som ble randomisert slik at hver person fikk to av tre mulige behandlinger, en på hver underarm: smøring med solkrem med brennmanetbeskyttende egenskaper, smøring med vanlig solkrem, og ingen smøring. Underarmene ble eksponert for våte brennmanettentakler lagt i en glasskål. Følgende registreringer ble gjort: Tid før smerte, hudforandringer etter fire minutter samt smerteintensitet etter ti minutter registrert på en VAS-skala.
\end{abstract}

Resultater. 13 av 25 som hadde fått brennmanetbeskyttende krem registrerte ikke noen smerter/ubehag etter fire minutters tentakkeleksponering, mot to av 25 og to av 26 som hadde fått hhv. forbehandling med vanlig solkrem og ingen forbehandling. Personer som hadde fått brennmanetbeskyttende krem registrerte i snitt lavere VAS-skår for smerte/ubehag etter ti minutter. Differansen var 10,6 mm (95\% KI 3,1-17,9) sammenliknet med vanlig solkrem og 14,2 mm (95\% KI 6,9-21,5) sammenliknet med ingen forbehandling. Det ble påvist et lavere antall underarmer med hudinflammasjon der det var benyttet brennmanetbeskyttende krem ( 6 av 25) sammenliknet med vanlig solkrem (11 av 25) og ingen forbehandling ( 12 av 26). Det var ikke statistisk signifikante forskjeller mellom vanlig solkrem og ingen forbehandling for noen av de tre utfallsmålene.

Fortolkning. Forbehandling med brennmanetbekyttende krem reduserte faren for å utvikle symptomer etter eksponering av brennmanettentakler.
Kim Alexander Tønseth

kim.tonseth@oslo-universitetssykehus.no Avdeling for plastikk-og rekonstruktiv kirurgi Oslo universitetssykehus

Torgrim Salvesen Andersen

AC-Sun Care Institute

Tønsberg

\section{Are Hugo Pripp}

Enhet for biostatistikk og epidemiologi

Oslo universitetssykehus

\section{Hans Erik Karlsen}

Biologisk institutt

Universitetet i Oslo

Drøbak

Kontakt med brennmaneter kan gi lokale plager i huden og i verste fall alvorlige reaksjoner. På verdensbasis regner man med at mer enn 150 millioner mennesker kommer i kontakt med maneter som forårsaker symptomer (1) og at minst 200 personer dør som følge av dette hvert år (2).

Etter direkte hudkontakt med brennmaneter kan det oppstå alt fra beskjedne lokale reaksjoner, som kløe og hudutslett, til alvorlige livstruende tilstander som anafylaktisk sjokk med sirkulasjons- og respirasjonskollaps. Graden av reaksjoner er avhengig av manetarten, hvor stor del av huden som blir eksponert for brennmanetens tentakler, og om personen er disponert for alvorlige reaksjoner. De fleste som søker sykehus etter kontakt med brennmaneter er barn og ungdom (3).

Maneter som er farlige for mennesker varierer i størrelse fra et par millimeter til arter opp mot to meter i diameter og med brenntråder (tentakler) som kan være flere titalls meter lange. Et felles kjennetegn ved disse (og andre) nesledyr er tentakler med nesleceller (cnidocytter), som aktiveres av kjemiske stoffer og/eller berøring. Når neslecellen aktiveres, skytes det ut et rør som overfører giftstoffer inn i byttet (4). Det er rimelig å anta at dersom en brennmanetbeskyttende solkrem blokkerer nesleceller og tilføring av gift hos én type neslecelle, så er sjansen stor for at den også beskytter mot nesleceller og gift fra andre beslektede maneter med samme type nesleceller.

Både rødbrennmaneten (Cyanea capillata) og blåbrennmaneten (Cyanea lamarckii) er vanlige langs norskekysten i perioder av året. De er dermed også de artene som oftest gir plager, selv om plagene som regel er forbigående og beskjedne. I tropiske og subtropiske farvann kan man risikere å møte maneter som opptrer i større kolonier, bl.a. såkalt portugisisk krigsskip (i Middelhavet) og kubemaneter, bl.a. sjøveps og irukandjikubemaneter (rundt Australia, Indonesia og Thailand). Både portugisisk krigsskip og de fleste arter av kubemaneter kan gi skader med livstruende symptomer.

Vi har tidligere publisert artikler i Tidsskriftet om utvikling av symptomer og funn ved brennmanetkontakt, virkningsmekanismer samt forebygging og behandling av brennmanetskader $(5,6)$. Varsling av brennmanetfare ved utsatte steder på aktuelle tidspunkt er et viktig forebyggende tiltak. Det er også mulig å beskytte huden med våtdrakt eller spesiallagede drakter som forhindrer at huden blir eksponert for brennmaneter. Likevel benyttes våtdrakter eller andre heldekkende drakter (stinging suits) av svært få badende i Norge. Todelt badetøy (bukse og overdel) er lite egnet til beskyttelse mot brennmanettentakler, selv om masketettheten tilfredsstiller kriteriene til «stinging suits», fordi manettentakler vil kunne komme i klem mellom badetøyet og kroppen og mekanisk stimuleres til aktivering. Det er rapporter som har vist at denne mekanismen har ført til dødsfall ved kontakt med irukandjimaneten, som imidlertid ikke finnes i norsk sjøvann (7).

De siste årene er det blitt utviklet solkremer med forebyggende effekt mot skader fra visse brennmanetarter $(1,8)$. Det er imidlertid blitt gjennomført få vitenskapelige studier der man har sett på disse, og ingen studier har testet effekten av slike beskyttelseskremer i forhold til blåbrennmaneten eller rødbrennmaneten. Rødbrennmanet har flere typer nesleceller og samtidig alle de typer nesleceller man finner hos blåbrennmanet (9). Det betyr

\section{Hovedbudskap}

- Bruk av solkrem med brennmanetbeskyttende egenskaper reduserte faren for å utvikle symptomer etter eksponering av brennmanettentakler

- Smerteintensiteten var lavere ved forbehandling med brennmanetbeskyttende krem sammenliknet med vanlig solkrem eller ingen forbehandling

- Vi fant ingen statistisk signifikante forskjeller i symptomutvikling mellom dem som fikk vanlig solkrem og dem som ikke hadde forbehandling 
at beskyttelseseffekter mot tentakler fra rødbrennmanet kan forventes å være like god mot tentakler fra blåbrennmanet.

Formålet med denne studien var å sammenlikne effekten av en kommersielt tilgjengelig brennmanetbeskyttende solkrem med effekten av vanlig vannfast solkrem og ingen forbehandling mot plager fra rødbrennmanet.

\section{Materiale og metode}

Dette er en randomisert studie utført i perioden september 2008 til desember 2009 ved Biologisk institutt i Drøbak, tilknyttet Universitetet i Oslo. Basert på tidligere studier ble det foretatt en styrkeberegning som viste at man måtte inkludere minst 24 personer (styrke $80 \%$, signifikansnivå $5 \%$ ) for å påvise en klinisk relevant forskjell i smerteangivelse på VAS-skala på $10 \mathrm{~mm}$ og antatt standardavvik til differansen på $7 \mathrm{~mm}$. Studien er registrert ved clinicaltrials.gov (registreringsnummer 2008-001519-39/NCT00693641) og er godkjent av regional etisk komité (registreringsnummer 6.2008.524).

\section{Testpersoner}

Gjennom oppslag på Biologisk institutt $i$ Drøbak og annonsering i lokale medier rekrutterte vi 38 frivillige personer (21 menn). Median alder var 26 år (spredning 20-48). Eksklusjonskriterier var alder under 18 år, kronisk sykdom, bruk av antihistaminer, systemiske eller lokale steroider eller andre allergimedisiner, bruk av topikale medisinske eller kosmetiske produkter på underarmene de siste 48 timene samt graviditet. Hudens pigmentering ble gradert etter Fitzpatricks inndeling i type $1-4(10)$.

\section{Metode}

Rødbrennmaneter ble innhentet fra Drøbaksundet i Oslofjorden samme dag eller dagen før testingen. Innhentingen ble foretatt varsomt ved hjelp av undertrykk i en bøtte slik at neslecellene ikke skulle bli aktivert eller manetene skadet på noe vis. Rødbrennmanetene ble plassert i store vannkar med automatisk gjennomstrømmende saltvann.

Det ble klargjort en liten rund glasskål med diameter $3,5 \mathrm{~cm}$, som ble fylt med 0,6 $\mathrm{g}$ avklippede tentakler (våte) for hvert hudområde som skulle testes. Et standardisert område på $16 \times 5 \mathrm{~cm}\left(80 \mathrm{~cm}^{2}\right)$ ble markert på begge underarmene til alle testpersonene.

Det ble så foretatt blokkrandomisering. Personene fikk to ulike forbehandlinger, én på hver arm, av følgende tre alternativer:

- smøring med 0,16 g solkrem med brennmanetbeskyttende innhold (SunCare solfaktor 15, AS-SunCare institute, Norge, basert på US Patent 7081247, (SafeSea) fra Nidaria Technology, Israel)

- smøring med 0,16 g vanlig solkrem (Nivea childrens sun lotion, solfaktor 15 )

- ingen smøring

Valg av forbehandling var ukjent for den personen (førsteforfatter) som skulle regi-

Tabell 1 Demografiske data etter behandlingsgruppe oppgitt som median (spredning) eller antall (\%)

\begin{tabular}{|c|c|c|c|}
\hline & $\begin{array}{c}\text { Brennmanet- } \\
\text { beskyttelse } \\
\text { og vanlig solkrem } \\
\text { ( } \mathrm{n}=12)\end{array}$ & $\begin{array}{l}\text { Brennmanet- } \\
\text { beskyttelse } \\
\text { og ingen krem } \\
\text { ( } n=13)\end{array}$ & $\begin{array}{c}\text { Vanlig solkrem } \\
\text { og ingen krem } \\
(n=13)\end{array}$ \\
\hline Alder, median (spredning) & $34(22-47)$ & $26(20-48)$ & $23(20-38)$ \\
\hline Kjønn, antall menn (\%) & $5(42)$ & $8(62)$ & $8(62)$ \\
\hline \multicolumn{4}{|l|}{ Hudtype (Fitzpatrick), n (\%)1 } \\
\hline Type 1 & $1(9)$ & $0(0)$ & $0(0)$ \\
\hline Type 2 & $1(9)$ & $5(38)$ & $5(38)$ \\
\hline Type 3 & $7(64)$ & $7(54)$ & $5(38)$ \\
\hline Type 4 & $2(18)$ & $1(8)$ & 3 (23) \\
\hline
\end{tabular}

Tabell 2 Tid mellom eksponering for brennmanettentakler og registrering av smerte/ubehag. Antall underarmer i hver tidsgruppe. Alle p-verdier oppgitt etter Bonferroni-korreksjon

$$
\begin{gathered}
\text { Ingen smerte/ } \\
\text { ubehag }{ }^{1}
\end{gathered}
$$

\section{Brennmanetbeskyttelse ${ }^{2}$}

Vanlig solkrem ${ }^{3}$

Ingen forbehandling

13

2

2

$$
\text { Smerte/ubehag }
$$

Tidlig

1

1

5

11

Sen

11

18

13
Totalt $(n)$
25

25

26

1 Disse personene registrerte heller ikke smerter etter avsluttet eksponering (> $240 \mathrm{~s}$ )

${ }^{2}$ Brennmanetbeskyttelse sammenliknet med vanlig solkrem $(p=0,32)$ og ingen forbehandling $(p<0,001)$

${ }^{3}$ Vanlig solkrem sammenliknet med ingen forbehandling $(p=0,55)$

strere reaksjonene hos testpersonene, som var blindet for bruk av solkrem med eller uten brennmanetbeskyttende egenskaper.

Huden på underarmene ble eksponert for de fripreparerte tentaklene i den lille glasskålen ved at skålen ble plassert opp ned på underarmen og fiksert med tape. Begge underarmene ble testet samtidig. Testpersonene skulle bevege og rotere armene forsiktig slik at tentaklene fikk en god kontaktflate mot huden. Glasskålen og innholdet ble så fjernet når testpersonen følte smerte/ubehag, senest etter fire minutter.

Følgende registreringer ble gjort:

- tid fra eksponering av tentaklene til registrering av smerte/ubehag

- hudforandringer etter fire minutter

- smerter/ubehag på underarm etter ti minutter, registrert med visuell analog skala (visual analog scale, VAS) fra $0-100$

Registreringene av tid til smerte/ubehag oppsto ble delt i tre kategorier: tidlig reaksjon (innen 45 sekunder), sen reaksjon (45 sekunder4 minutter), og ingen smerte/ubehag innen fire minutter, da eksponeringen ble avsluttet.

Hudforandringer etter fire minutter ble klassifisert som ingen hudforandringer, lette fargeforandringer, markerte fargeforandringer, strukturforandringer eller hudblemmer.
Lege med behandlingsmuligheter for alvorlige allergiske reaksjoner var til stede under undersøkelsen.

\section{Statistisk analyse}

Demografiske data er presentert med median (spredning) eller antall personer (\%). Deskriptive sammenlikninger av tid frem til smerte/ubehag mellom type forbehandling er presentert med Kaplan-Meier-kurver. Det ble ikke utført logranktest ettersom observasjonene var parede.

Med tre randomiserte forbehandlinger og parede data innad i personen registrerte man effekten av to forbehandlinger for hver person - én for hver arm. Dataene ble analysert med med Generalized Estimating Equations (GEE) for ordinale utfall der man antok en utskiftbar kovarians mellom armene for hver person.

Det ble gjort parvise sammenlikninger mellom de tre forbehandlingene. Oppgitte p-verdier er Bonferroni-korrigert. Registrering av smerter/ubehag på VAS-skala ble analysert med en lineær blandet modell med et tilfeldig konstantledd (random intercept) for å ta hensyn til sammenheng innad i hver person. Statistisk signfikans ble definert ved p-verdi $<0,05$. De statistiske analysene ble utført med SPSS, versjon 18 (SPSS Inc, Chicago, IL, USA). 


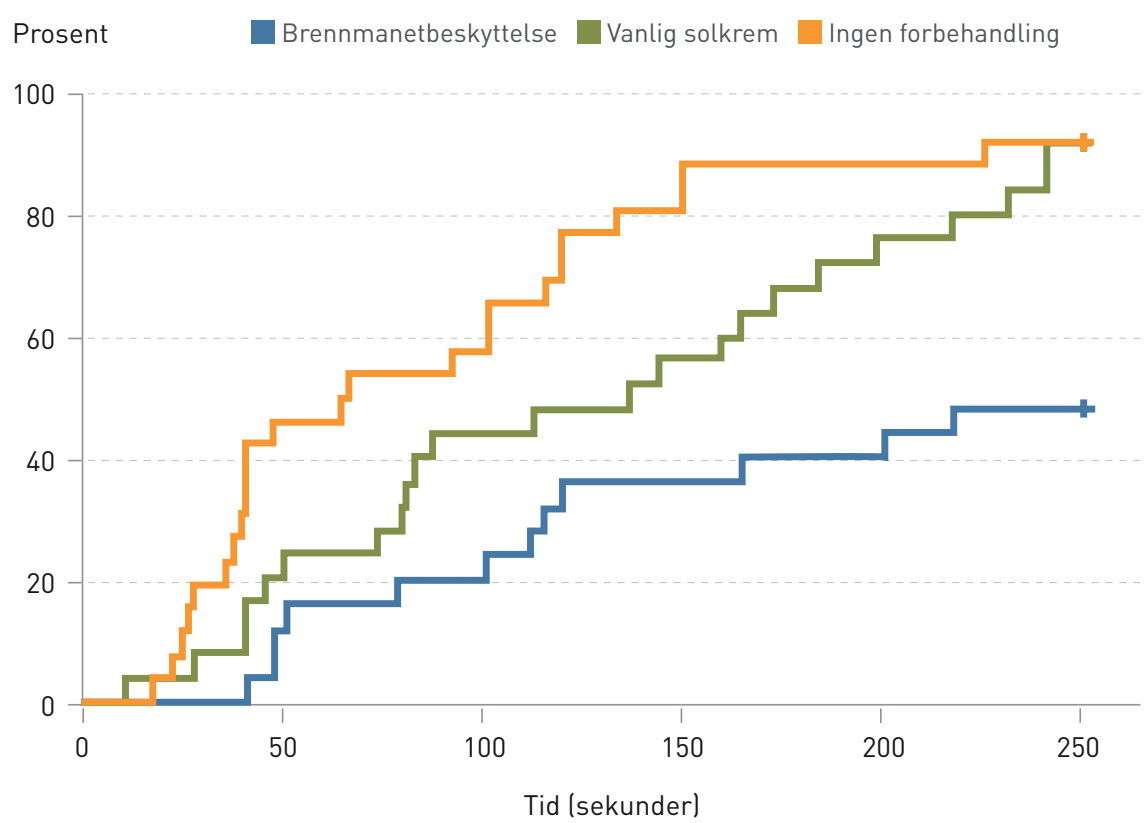

Figur 1 Kumulativ prosentandel av testpersoner som registrerte smerte etter eksponering av brennmanettentakler i forhold til tid (Kaplan-Meier-kurve)

\section{Resultater}

Demografiske data for personene i de ulike gruppene fremgår av tabell 1. Av dem som hadde fått brennmanetbeskyttende krem, var det 13 av 25 som ikke registrerte noen smerter/ubehag etter fire minutters tentakkeleksponering, mot to av 25 og to av 26 som hadde fått hhv. forbehandling med vanlig solkrem og ingen forbehandling (tab 2). Figur 1 gir en visualisering av tid frem til smerte/ubehag med og uten forbehandling.

Det var forskjeller i klinisk synlige

hudreaksjoner mellom bruk av brennmanetbeskyttende krem og hhv. vanlig solkrem $(p=0,03)$ og ingen forbehandling $(p=0,006)(\operatorname{tab} 3)$. Det ble ikke funnet forskjell mellom vanlig solkrem og ingen forbehandling. Personer som hadde fătt brennmanetbeskyttende krem registrerte i snitt lavere VAS-skår for smerte/ubehag etter ti minutter enn både vanlig solkrem (differanse 10,6 ; $95 \% \mathrm{KI} 3,1-17,9)$ og ingen forbehandling (differanse 14,2; $95 \%$ KI $6,9-21,5)(\operatorname{tab} 4)$. Det ble ikke funnet for-

Tabell 3 Grad av inflammasjon i hud fire minutter etter eksponering av brennmanettentakler. Alle p-verdier oppgitt etter Bonferroni-korreksjon

\begin{tabular}{|c|c|c|c|c|c|c|}
\hline & \multicolumn{6}{|c|}{ Hudforandring } \\
\hline & $\begin{array}{l}\text { Ingen } \\
\text { hudforand- } \\
\text { ring }\end{array}$ & $\begin{array}{l}\text { Lett farge- } \\
\text { forandring }\end{array}$ & $\begin{array}{c}\text { Markert } \\
\text { farge- } \\
\text { forandring }\end{array}$ & $\begin{array}{l}\text { Struktur- } \\
\text { forandring }\end{array}$ & $\begin{array}{l}\text { Hud- } \\
\text { blemmer }\end{array}$ & Totalt (n) \\
\hline $\begin{array}{l}\text { Brennmanet- } \\
\text { beskyttelse }\end{array}$ & 19 & 4 & 2 & 0 & 0 & 25 \\
\hline Vanlig solkrem² & 14 & 5 & 5 & 1 & 0 & 25 \\
\hline Ingen forbehandling & 14 & 5 & 7 & 0 & 0 & 26 \\
\hline
\end{tabular}

Tabell 4 Registrering av smerte/ubehag på visuell analog skala (VAS) ti minutter etter eksponering av brennmanettentakler. Gjennomsnittlig VAS-skår estimert fra den lineære blandede modellen

\section{n}

Brennmanetbeskyttelse ${ }^{1}$

Vanlig solkrem²

Ingen beskyttelse

Brennmanetbeskyttelse sammenliknet med vanlig solkrem ( $p=0,003)$ og ingen forbehandling $(p<0,001)$

2 Vanlig solkrem sammenliknet med ingen forbehandling $(p=0,65)$ skjell mellom vanlig solkrem og ingen forbehandling $(\mathrm{p}=0,65)$.

Det ble ikke registrert alvorlige lokale eller systemiske reaksjoner under eller etter testingen.

\section{Diskusjon}

I denne studien har vi testet effekten av brennmanetbeskyttende krem sammenliknet med vanlig solkrem og ingen forbehandling ved eksponering av brennmanettentakler. Vi fant at bruk av brennmanetbeskyttende krem reduserte antall personer som fikk plager og antall objektive funn. Plagene var også mindre.

Disse resultatene samsvarer godt med de få publiserte studiene om bruk av beskyttende krem mot brennmanetplager, selv om studiene har noe forskjellig metodologi og andre typer brennmaneter er benyttet. I en feltstudie fra Mexicogolfen undersøkte man brennmanetbeskyttelse (SafeSea) mot vanlig solkrem (Coppertone) på ti frivillige snorklere (1). Høyre og venstre kroppshalvdel ble påført en av de to kremene. Personene snorklet til sammen 82 ganger i sjøvann i rundt 30 minutter. Det ble registrert to symptomgivende kontakter med brennmanet på de hudområdene som hadde fått brennmanetbeskyttelse, mot 11 på de områdene som var blitt påført vanlig solkrem $(p=0,02)$. I en annen studie hvor metodologien er mer lik vår studie, ble 24 personer undersøkt med brennmanetbeskyttende krem (SafeSea) eller vanlig solkrem (Coppertone) på underarmen (8). Av de 12 testpersonene som ble eksponert for brennameneten Chrysaora fuscescens, utviklet alle erytem og smerter på hudområder som var smurt med vanlig solkrem, mens det ble påvist erytem og registrert smerter hos kun to testpersoner på hudområder som var smurt med brennmanetbeskyttende krem $(p<0,01) .12$ personer ble testet mot kubemaneten Chiropsalmus quadrumanus, der erytem og smerter ble registrert hos henholdsvis ti og ni av dem som hadde fått vanlig solkrem, mot én og tre av dem som hadde fătt brennmanetbeskyttende krem $(\mathrm{p}<0,01)$.

Fordelen med vår studie sammenliknet med tidligere studier er et høyere antall testpersoner og at den brennmanetbeskyttende kremen også er testet opp mot ingen forbehandling. I studien prøver vi dessuten $\mathrm{i}$ større grad å måle tid før smerte/ubehag oppstår og å sammenlikne effekten av den brennmanetbeskyttende kremen med vanlig solkrem eller ingen krem. De manetene som hyppigst forekommer i det norske sjøvannet ble benyttet. Vi mener derfor at denne studien er adekvat for nordeuropeiske forhold.

Svakheten med vårt oppsett var at vi undersøkte effekten av tre ulike forbehandlinger, der hver person bare fikk to av disse. Vi mener imidlertid å ha tatt høyde for dette i våre statistiske analyser. Bakgrunnen for å sammenlikne bruk av den brennmanetbeskyttende kremen med både vanlig solkrem og ingen forbehandling var at elektronmikroskopiske studier har vist at vanlig vannfast 
solkrem kan ha en beskyttende effekt mot nesleceller sammenliknet med ingen forbehandling (11). Vi fant større forskjeller mellom brennmanetbeskyttende krem og ingen forbehandling enn mellom brennmanetbeskyttende krem og vanlig solkrem, men ingen statistisk signifikante forskjeller mellom vanlig solkrem og ingen forbehandling. Det er mulig at man ved å øke antall testpersoner kunne ha påvist en slik forskjell, men det er usikkert om dette ville ha hatt klinisk signifikant relevans. I tillegg bør det bemerkes at vi ikke hadde negativ kontroll og at kun forbehandling med brennmanetbeskyttelse og vanlig solkrem var blindet for forsøkspersonen. Denne blindingen var ikke mulig for dem som ikke fikk forbehandling, noe som kan innvirke på registreringen til forsøkspersonene.

Som de fleste sjøbadere har opplevd, oppstår smerter/ubehag relativt umiddelbart etter eksponering av brennmanettentakler, tilsvarende det tidspunktet neslecellene skyter giftstoffene inn i huden. Vanligvis skjer dette ved førstegangs berøring. I vår studie fikk vi registrering av smerte/ubehag på forskjellige tidspunkt i løpet av de fire minuttene personene ble eksponert for tentakler, selv om svært mange av dem som ikke fikk forbehandling registrerte smerte/ubehag innen 150 sekunder. Dette kan skyldes at vi testet personene for en relativt liten mengde brennmanettentakler på et relativt lite område. I tillegg var noen av neslecellene allerede aktivert ved forflytning fra sjø til testlokalet og dermed ikke lenger potensielt skadelige. For å være sikre på at noen av neslecellene ble aktivert mot testpersonenes hud og dermed kunne fremprovosere smerte/ ubehag, valgte vi en relativt lang eksponeringstid. Vi undersøkte ikke effekten av lengre eksponeringstid enn fire minutter, men vi mener denne tiden er tilfredsstillende sett $\mathrm{i}$ forhold til forventet eksponeringstid i vanlig sjøvann. Av dem som ikke utviklet smerter/ubehag under eksponering, var det ingen som utviklet smerter/ubehag etter at tentaklene ble fjernet. Dette kan tyde på at faren for utvikling av symptomer i tiden etter eksponering er liten.

Den brennmanetbeskyttende effekten kan være knyttet til flere forhold (1). Kremen er svært hydrofob og reduserer derfor antall tentakler som kommer i kontakt med huden. Kremen inneholder glykosaminoglykaner, som likner de som er på brennmaneten, og reseptorantagonister som ved aktivering trigger neslecellereseptorene. Kremen inneholder dessuten stoffer som blokkerer kalsium- og magnesiumutvekslingen i neslecellenes nesleblærer og reduserer derfor den osmotiske kraften til å overføre neslecellegift. Selv om dette kan redusere mengden av giftstoffer en person blir utsatt for, vil ikke kremen nøytralisere effekten av giften som eventuelt vil komme inn i huden.

Behandlingsstrategien som vi tidligere har skrevet om i Tidsskriftet $(5,6)$ er derfor fortsatt aktuell for de personene som utvikler lokale eller systemiske symptomer. Etter eksponering bør brenntråder fjernes forsiktig med pinsett og/eller skylles vekk med sjøvann. Man bør ikke bruke midler til inaktivering av neslecellene såfremt man ikke sikkert vet midlets virkningsmekanisme mot den spesifikke maneten. Dette kan i verste fall føre til en forverring, som for eksempel bruk av eddik ved rødbrennmaneten. Etter at alle brenntråder er fjernet, kan man dempe lokale reaksjoner med lidokaingel eller kortikosteroidsalve. Det kan også vurderes perorale medikamenter som paracetamol, ikke-steroide antiinflammatoriske midler, antihistaminer og steroider. Ved systemiske reaksjoner bør pasienten observeres eller innlegges.

\section{Kim Alexander Tønseth (f. 1974)}

er dr.med. og spesialist i plastikkirurgi. Han har siden 2007 vært avdelingssjef ved Avdeling for plastikk- og rekonstruktiv kirurgi, Rikshospitalet.

Forfatteren har fylt ut ICMJE-skjemaet og oppgir ingen interessekonflikter.

\section{Torgrim Salvesen Andersen (f. 1973)}

har de siste årene deltatt i flere studier og fors $\varnothing k$ vedrørende deaktivering av nesleceller, forebygging og smertelindrende behandling av brennmanetskader.

Forfatteren har fylt ut ICMJE-skjemaet og oppgir å ha aksjer i AC-SunCare Institute as, som er produsent av brennmanetbeskyttelseskremen SunCare.

\section{Are Hugo Pripp (f. 1971)}

er biostatistiker ved Enhet for biostatistikk og epidemiologi, Oslo universitetssykehus. Forfatteren har fylt ut ICMJE-skjemaet og oppgir ingen interessekonflikter.

\section{Hans Erik Karlsen (f. 1956)}

er dr. scient., førsteamanuensis og bestyrer ved Marinbiologisk feltstasjon i Drøbak, tilknyttet Universitetet i Oslo.

Forfatteren har fylt ut ICMJE-skjemaet og oppgir ingen interessekonflikter.

Litteratur

1. Boulware DR. A randomized, controlled field trial for the prevention of jellyfish stings with a topical sting inhibitor. J Travel Med 2006: 13: 166-71.

2. Fenner PJ, Williamson JA. Worldwide deaths and severe envenomation from jellyfish stings. Med J Aust 1996; 165: 658-61.

3. Forrester MB. Epidemiology of jellyfish stings reported to poison centers in Texas. Hum Exp Toxicol 2006; 25: 183-6.

4. Kass-Simon G, Scappaticci AA Jr. The behavioral and developmental physiology of nematocysts. Can J Zool 2002; 80: 1772-94

5. Tønseth KA. Helseskade ved kontakt med brennmaneter. Tidsskr Nor Legeforen 2007; 127: 1777-8.

6. Tønseth KA, Andersen TS, Karlsen HE. Brennmanetskader. Tidsskr Nor Legeforen 2009; 129 1350.

7. Gershwin L, Dabinett K. Comparison of eight types of protective clothing against Irukandji jellyfish stings. J Coast Res 2009; 25: 117-30.

8. Kimball AB, Arambula KZ, Stauffer AR et al. Efficacy of a jellyfish sting inhibitor in preventing jellyfish stings in normal volunteers. Wilderness Environ Med 2004; 15: $102-8$

9. Östman C. Hydman J. Nematocyst analysis of Cyanea capillata and Cyanea lamarckii. Sci Mar 1997; 61: 313-44

10. Fitzpatrick TB. The validity and practicality of sun-reactive skin types I through VI. Arch Dermatol 1988; 124: 869-71.

11. Heeger T, Möller H, Mrowietz U. Protection of human skin against jellyfish (Cyanea capillata) stings. Mar Biol 1992; 113: 669-78.

Mottatt 30.5. 2011, første revisjon innsendt 29.2 2012, godkjent 10.5. 2012. Medisinsk redaktør Siri Lunde. 